\title{
User-Driven Product Data Manager System Design
}

With the infusion of information technologies into product development and production processes, effective management of product data is becoming essential to modern production enterprises. When an enterprise-wide Product Data Manager (PDM) is implemented, PDM designers must satisfy the requirements of individual users with different job functions and requirements, as well as the requirements of the enterprise as a whole. Concern must also be shown for the interrelationships between information, methods for retrieving archival information and integration of the PDM into the product development process. This paper describes a user-driven approach applied to PDM design for an agile manufacturing pilot project at Sandia National Laboratories that has been successful in achieving a much faster design-to-production process for a precision electro mechanical surety device.

\section{DISCLAIMER}

This report was prepared as an account of work sponsored by an agency of the United States Government. Neither the United States Government nor any agency thereof, nor any of their employees, makes any warranty, express or implied, or assumes any legal liability or responsibility for the accuracy, completeness, or usefulness of any information, apparatus, product, or process disclosed, or represents that its use would not infringe privately owned rights. Reference herein to any specific commercial product, process, or service by trade name, trademark, manufacturer, or otherwise does not necessarily constitute or imply its endorsement, recommendation, or favoring by the United States Government or any agency thereof. The views and opinions of authors expressed herein do not necessarily state or reflect those of the United States Government or any agency thereof.

\section{MASTER}




\section{DISCLAIMER}

Portions of this document may be illegible in electronic image products. Images are produced from the best available original document. 


\section{User-Driven Product Data Manager System Design}

\section{Introduction}

Over the past decade, engineering and manufacturing enterprises have been a prime market for developing information technologies. Computer-Aided Design (CAD) tools have matured to a level at which nearly all facets of design may be accomplished using electronic design representations. Virtual prototype testing allows many design decisions to be made reliably on the basis of computer simulations. Computer-Aided Manufacturing (CAM) applications streamline the process of generating machine tool paths from design data. Similarly, assembly planners and robotic code generators automate many of the more time-consuming steps required for robotic assembly. These advances result in an overwhelming proliferation of electronic information that must be managed during and following product development.

The information management dilemma faced by modern engineering and manufacturing enterprises is compounded by two additional factors. First, as concurrent engineering principles are more fully integrated into corporate business practices, efficient mechanisms for information dissemination, storage, access and retrieval are required, as are mechanisms for controlling such facets of product data as read/write file permissions and version control (Donlin, 1994, SDRC, 1992). Secondly, the information technologies discussed above, implemented within an agile manufacturing paradigm, dramatically increase the rate at which information is created, the volume of information that must be interacted with at any given time and the pace at which information is utilized (Goodwin \& Priess, 1992).

Recently, the Agile Product Realization for Innovative Electro Mechanical Devices (A-PRIMED) project at Sandia National Laboratories (SNL) addressed the above concerns through implementation of a product data management (PDM) system. Implementation of the PDM occurred as part of a general communications strategy that also included infrastructure development, e-mail and Interactive Collaborative Environments (Ashby \& Lin, 1994). The A-PRIMED project posed particularly stringent demands on the PDM due to its use of a parent/child design approach that led to there being multiple versions of multiple 
designs in progress at any time (Parratt et. al., in preparation). Furthermore, A-PRIMED achieved much faster product development times through pre-qualification of a design parameter space and the subsequent reliance on corporate history electronically archived within the PDM (Diegert et. al., submitted). Through these innovations, A-PRIMED has been successful in shortening the designto-production process for a pin-in-maze discriminator, a precision electro mechanical surety device (see Figure 1), to 24 days or less, from what previously would have been several months to over a year. This paper describes the user-driven design methodology employed to develop user requirements and incorporate those requirements into the PDM design used for the A-PRIMED project.

\section{Insert Figure 1 - Pin-in-Maze Discriminator}

\section{PDM Requirements and Infrastructure}

Due to the immediacy of A-PRIMED's need for a PDM, the decision was made early to purchase a commercial application, with the stipulation that the application be relatively open-ended with regard to database and user interface design.

As shown in Table 1, the A-PRIMED project encompassed a broad representation of engineering and production functions. To assure that the PDM design addressed the needs of all participants in the enterprise, representatives of each functional area were included in the PDM design team. While some project team members had experience using configuration management applications during software development, no one had ever used such applications for mechanical design or manufacturing, and there had been no previous efforts at enterprise-wide product data management. For this reason, the first step in design and implementation of the PDM was the familiarization of project team members with PDM concepts and capabilities. 
Table 1. Engineering Functions Incorporated Into PDM

Mechanical Design

Drafting

Engineering Analysis

Manufacturing

Testing

Automated Assembly

Quality Assurance

Communications

Project Management

Three metaphors were identified to facilitate thinking and discussions about the PDM:

(1.) Project File Cabinet - a centrally located, readily accessible repository where all project information is stored and all team. members have unrestricted access.

(2.) Staging Area - a common area where work in progress is stored when being transferred between team members.

(3.) Library or Archive - a central repository where information is archived and may be accessed at later dates.

Based on these metaphors, and consideration of planned and target work processes and business practices (Forsythe \& Ashby, in preparation), the following requirements were identified:

- the PDM must be compatible with CAD and CAM applications being used (ProEngineer and ProManufacture by Parametrics Technologies) including the capability to transparently enter application-specific information (e.g., associative links between assembly models and models of constituent parts) into the database

- the PDM must enable integration with other applications through a Standard Query Language (SQL) interface and Application Programming Interface (API)

- the PDM must be capable of managing all file formats in use by the enterprise 
- the PDM must allow read/write/delete permission status of PDM users to be designated on a file-by-file basis

- the PDM must provide version control in that only one user can make changes to a file at a time

- the PDM must provide designated users automatic electronic notification when specified files are modified

- the PDM must allow users to specify attributes, and associations to other files during file entry, and enable database searches on the basis of these attributes and associations

These factors led to the selection of CMS/Pro by Workgroup Technologies as the PDM application, after which the PDM and supporting infrastructure shown in Figure 2 were implemented. This infrastructure included a centralized vault and server, a secure gateway to access the PDM on Sandia's restricted network from the external open network (Ang et al., submitted), access for users residing on nine separate local area networks and access from UNIX, Mac and PC platforms.

\section{Insert Figure 2 - Infrastructure}

\section{PDM Design}

The next step in implementation of the PDM was to design the database class structure, which are categories in which files are placed, and the attribute structure, which are variables used to describe files. The PDM allowed the database to be hierarchically structured using classes, with each class distinguished on the basis of a unique set of file attributes. In addition to class-specific attributes, there were also common attributes that applied to all files in all classes. Prior to the first PDM design team meeting, each member was asked to make lists of the information they used and information they generated, and distribute these lists to other members of the PDM design team via electronic mail.

At PDM design team meetings, a hypothetical product design was traced as it progressed through the design and production cycle. Product information generated at each point in the cycle was noted, as were the relationships between information generated at each point. Early on, it was apparent that the product, as defined by 
customer requirements, provided a common link with which all other information generated in the product development process could be referenced. Thus, the convention was accepted that each product would be given a unique name based on the customer or application for which it is intended. Since the basic representation of the product would be a CAD model of the assembled parts, all files generated during the product development process would be associatively linked to this assembly model. Thus, if a search was conducted for any given product design to find associated files and no other restrictions placed on the search, all subassembly, part, requirements, machine tool path, robotic assembly code, physical testing, computer simulation analysis and qualification files developed during the product development effort would be located.

The A-PRIMED project employs a Parent/Child design approach whereby the objective is to design not a single electro mechanical device (point design), but instead, to design a family of electro mechanical devices (Parratt et. al., in preparation). Based on prior experience, analysis and testing, and knowledge of the capabilities of machining and robotic assembly processes, a design space has been defined on the basis of specific design parameters and the range of values along each parameter that can be designed and built to, with confidence. Design parameters take the form of potential customer requirements (e.g., operating temperature, size, input voltage) and provide the framework for customer interactions during new product development. With these considerations in mind, the decision was made to structure the PDM class in which product designs would be stored relative to the parameters of the design space. This makes it possible to specify a PDM search of design files on the basis of a new customer's requirements, and subsequently, identify all existing designs that meet those requirements. Likewise, if no existing files meet the customer's requirements, the criteria may be relaxed along one or more parameters the design engineer knows are outside previous experience, and all existing designs that approximate the customer's requirements may be found. At this point, the design engineer may conduct a search by association to find analysis and test files that may provide clues to weak points in the earlier design and design modifications needed to meet the new customer's requirements.

There was an agreed upon objective that file attributes would be utilized in conducting searches. This approach would support the general strategy of providing many different paths for finding any 
given file, and since a file could only reside in one class, classes defined broadly, on the basis of general functional areas, would minimize uncertainties in assigning files to classes (e.g., all testing files would go in the testing class). As shown in Figure 3, three broad classes were defined, Automated Assembly, Engineering and Manufacturing, and within each broad class, subclasses were defined to accommodate distinct categories of information that could not be described with a common set of attributes.

Insert Figure 3 - Class Structure

\section{PDM Class-Specific Attributes}

With an agreed upon PDM strategy and class structure, the next step was to define the attribute structure for each class and develop associated user interfaces. At this point, the PDM design effort turned from team meetings to individual meetings with representatives of each functional area. Initially, there was a general discussion of the types of information generated by each functional area, characteristics of different types of information, and in particular, what cues were used to remember information. The question was frequently asked: if you had to find this file five years from today, what cues would you use? Information gained during initial discussions was used to develop prototypes of the attribute structure and user interface for each class, and through a series of two to three follow-ups, the attribute structure and user interface for each class were refined to reach the final fielded version.

The engineering/design/mechanical/assembly class was designated as the repository for product designs. As shown in Figure 4 , the parameters of the design space are each represented as attributes. This enables the database of existing files to be searched on the basis of customer requirements, as shown in Figure 5. The design engineer also indicated that in retrieving an archived design, it would be useful to have attributes specifying the customer, application (e.g., automotive, satellite), design intent (e.g., light weight), unique considerations (e.g., salt water tolerant), unique materials, and partners or suppliers for each product design. As shown in Figure 6 , the test engineer said it would be helpful to have attributes indicating the project requesting testing, the product tested, a description of the test set-up and the combination of tests applied. Similarly, a custom interface was developed for each class 
that accommodated the unique considerations of each job function within the product development process.

\author{
Insert Figure 4 - Design Attributes \\ Insert Figure 5 - Design Search \\ Insert Figure 6 - Testing Attributes
}

\title{
Discussion
}

The previous sections have illustrated user-driven design in the development of a corporate PDM. A user-driven process accomplished several goals: (1.) through design participation, each user assured that the requirements of their functional area were met; (2.) by including all functional areas in the design process, a total PDM system design was attained that satisfied both individual and enterprise needs; (3.) discussions of the inter-relationships between product data fostered project-wide concurrent engineering; and (4.) the PDM design effort served as a foundation for development and refinement of the agile product development process. The key ingredients to the success of this effort are inclusion of all functional areas on the design team, emphasis on an enterprise model that encompassed all elements of product development and the use of prototypes to allow users to see how alternative designs would look and operate. It is further recommended that consideration be given to incorporating sufficient flexibility into the PDM design so that it accommodates evolving patterns of usage and minimally restricts the ability to adapt the PDM to the changing needs of the enterprise. The PDM design effort described in this paper has been successful, as evidenced by the APRIMED project demonstrating the use of electronic media to achieve a substantial reduction in the time required to develop a new product, based on unique customer requirements.

\section{Acknowledgments}

The author would like to thank Bob Easterling for his thoughtful review of this paper. This work was supported by the United States Department of Energy under Contract DE-AC04-95/AL85000. 


\section{References}

Ang, J.A., Machin, G.D. \& Marek, E.L. (submitted). The Technology Information Environment with Industry (TIE-IN): A Mechanism for Accessing Laboratory Solutions. 1995 Agile Manufacturing Enterprise Forum.

Ashby M.R. \& Lin, H.W. (1994). Interactive Collaborative Environments (ICE): Platform Independent X Application Sharing and Multi-Media over Wide Area Networks at Sandia National Laboratories. In the Proceedings of the Fifth International Symposium on Robotics and Manufacturing.

Diegert, K.V., Easterling, R.G., Ashby, M.R., Benavides, G.L., Forsythe, C., Jones, R.E., Longcope, D.B. \& Parratt, S.W. (submitted). Achieving Agility through Parameter Space Qualification. 1995 Agile Manufacturing Enterprise Forum.

Donlin, M. (1991). Data Management Tools Tie Frameworks to Concurrent Engineering. Computer Design, April 1, 28-32.

Forsythe, C. \& Ashby, M.R. (in preparation). Process Development for Agile Product Realization.

Goldman, S. \& Preiss, K. (1992). 21st Century Manufacturing Enterprise Strategy. Volume 2. Infrastructure. Bethlehem, PA: Lehigh University.

Parratt, S.W., et. al. (in preparation). Parent/Child Design Paradigm.

SDRC. (1992). How to Make Concurrent Engineering Work. Part 3. Core Technology for Successful Implementation. Machine Design, October 22, 119-122. 
User-Driven PDM Design

Figure 1. Pin-in-Maze Discriminator

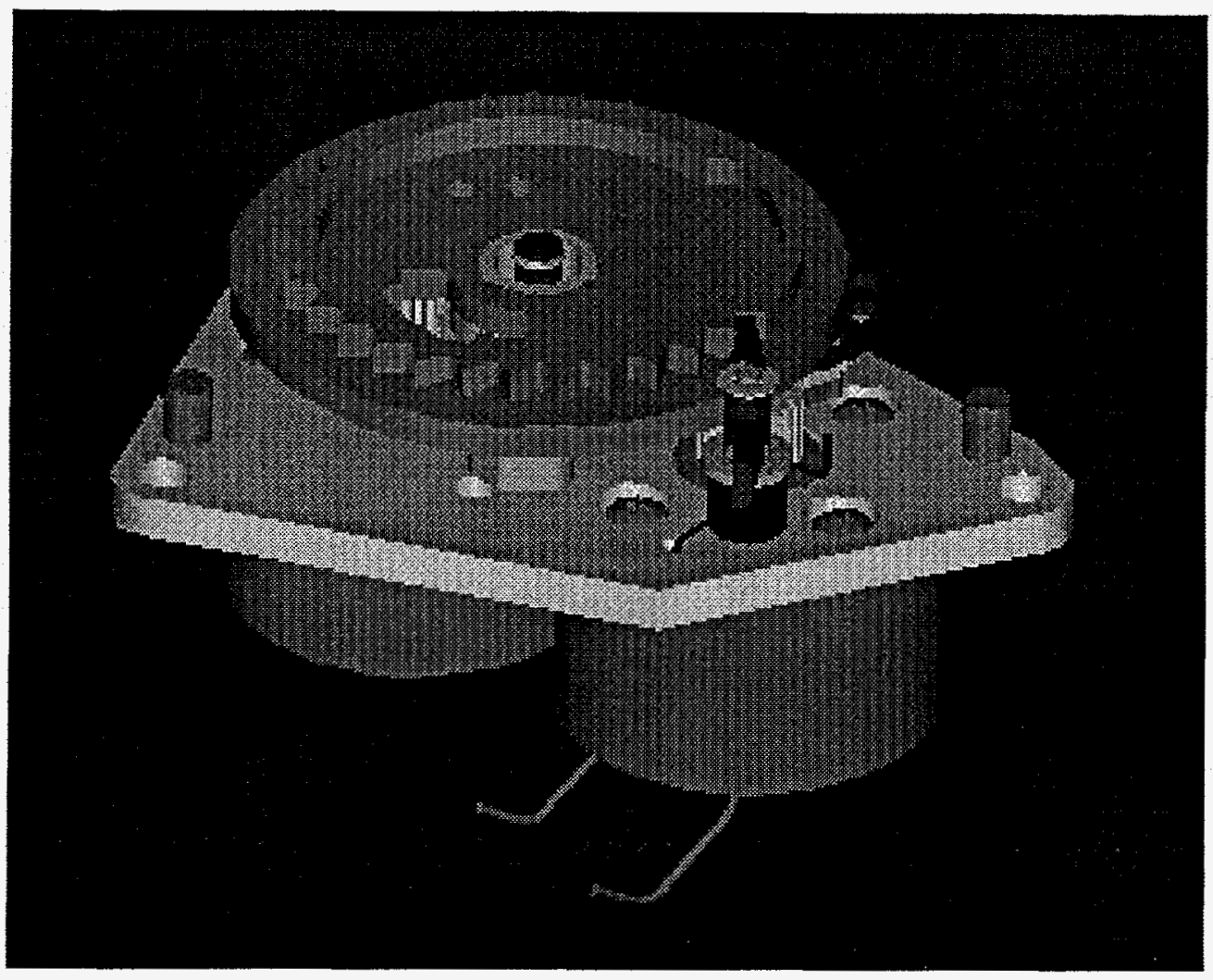

Page 10 


\section{User-Driven PDM Design}

Figure 2. PDM Infrastructure

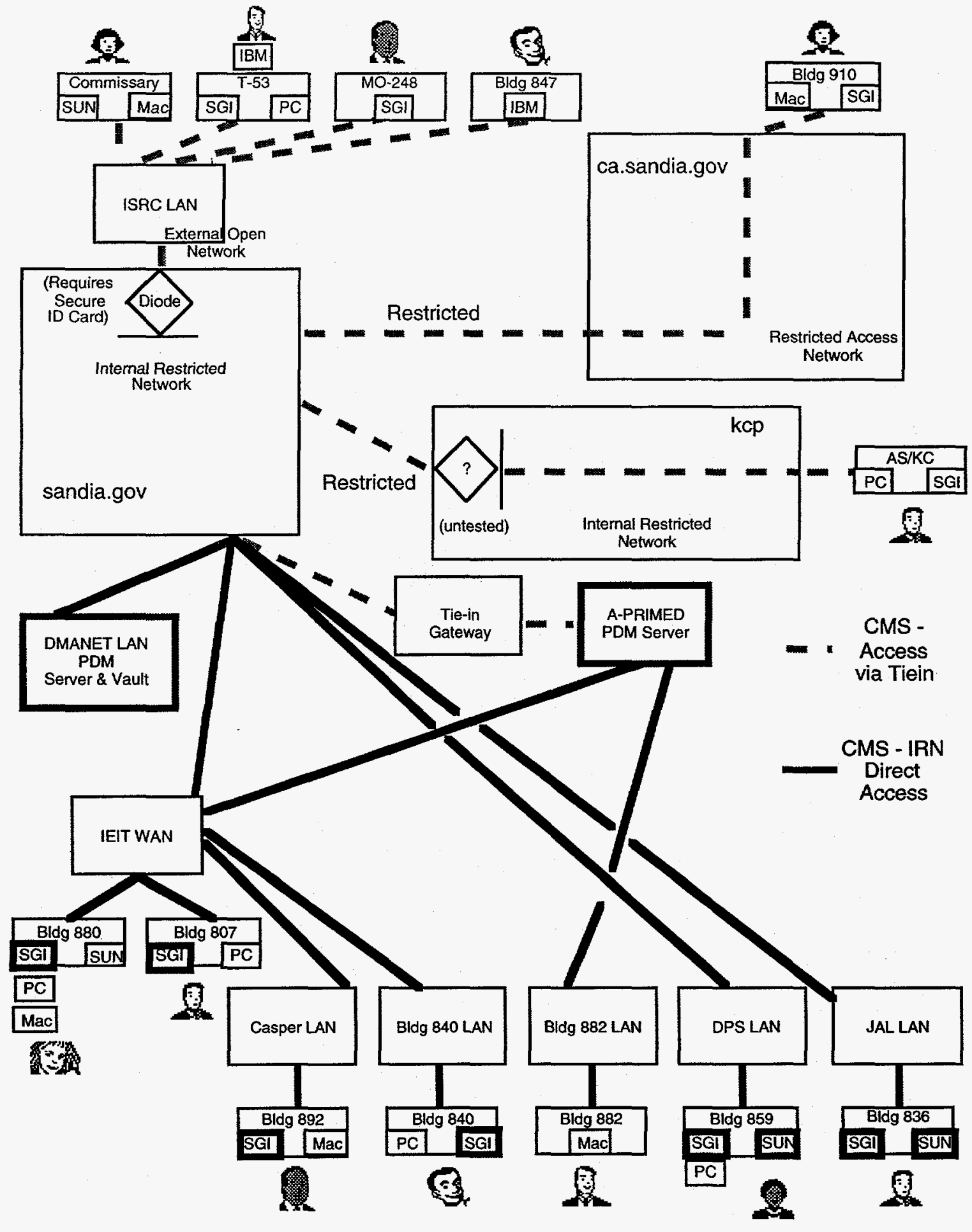

Page 11 
User-Driven PDM Design

\section{Figure 3 PDM Class Structure}

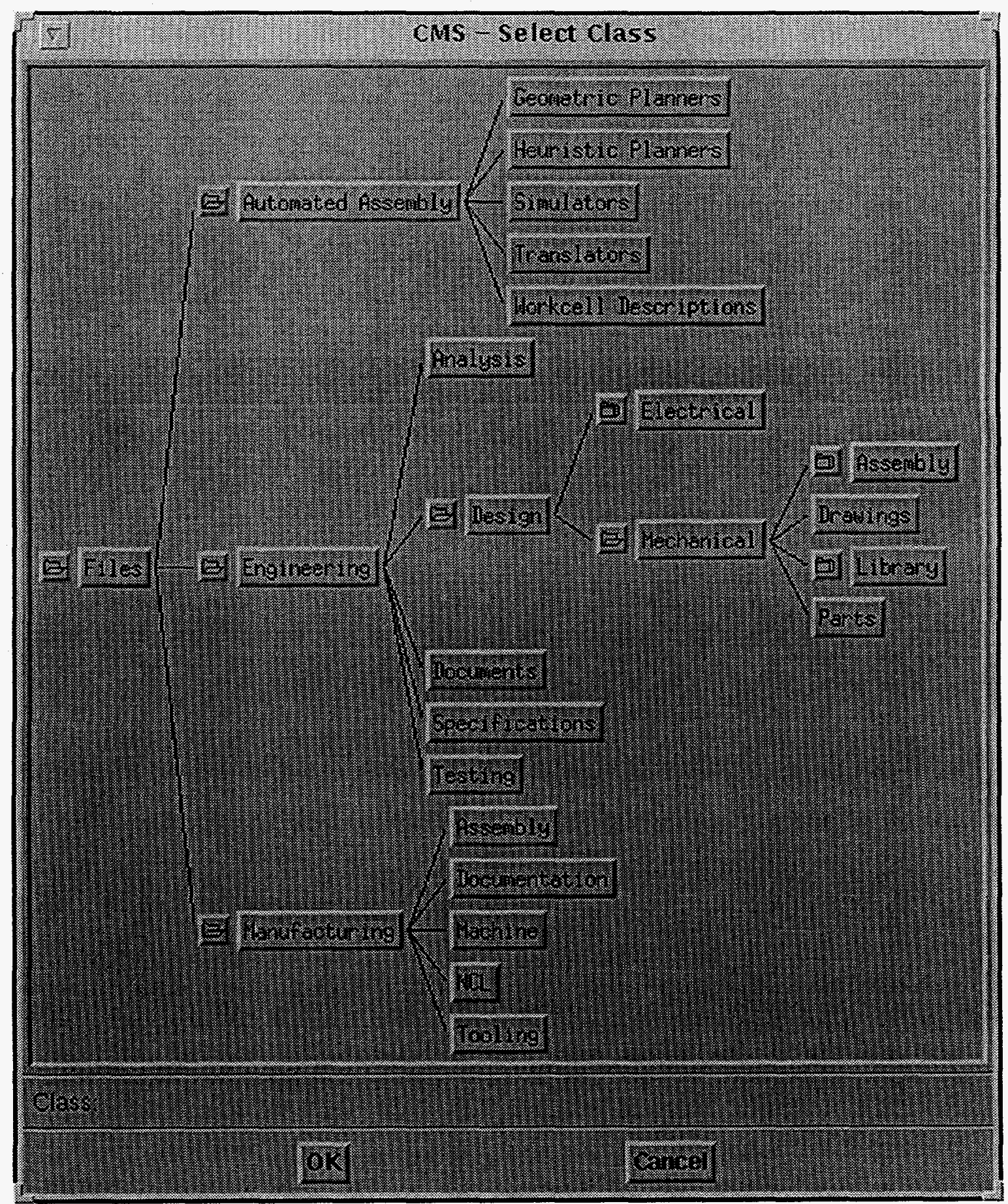




\section{Figure 5 Product Attribute Structure from Design Assembly Class}

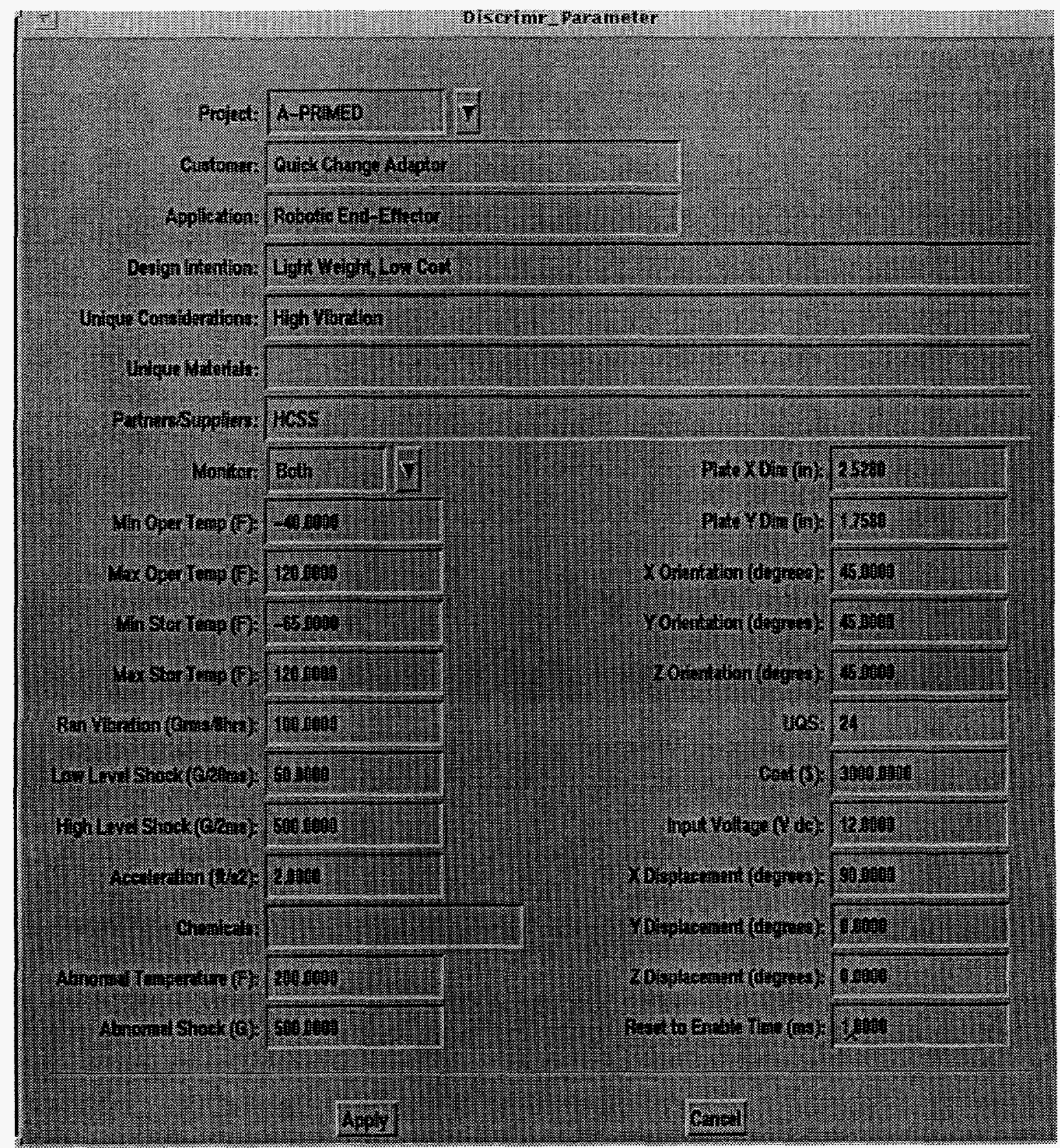


Figure 4 Example of Product Database Search Based on Customer Requirements

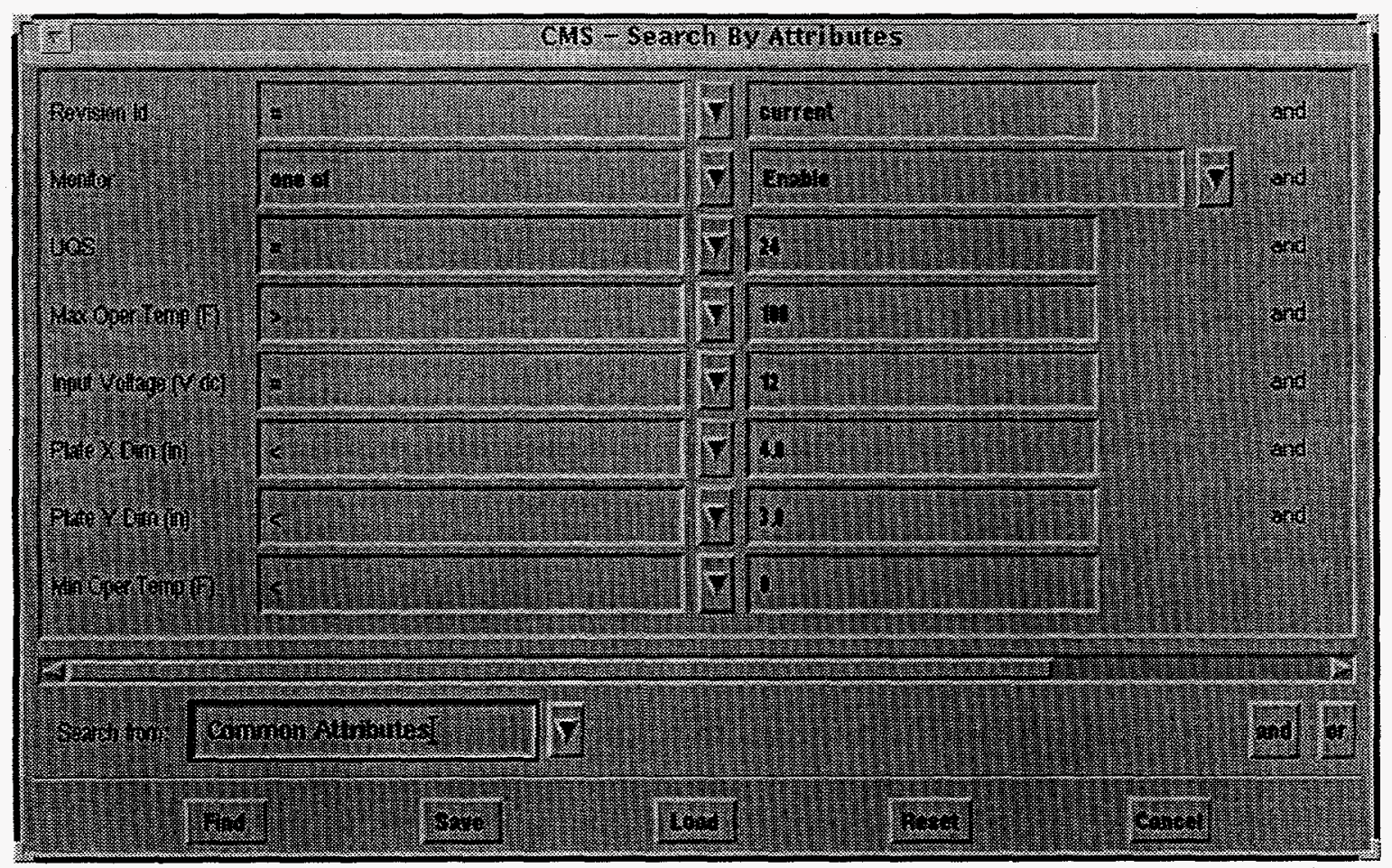


User-Driven PDM Design

Figure 6 Attribute Structure for Testing Class

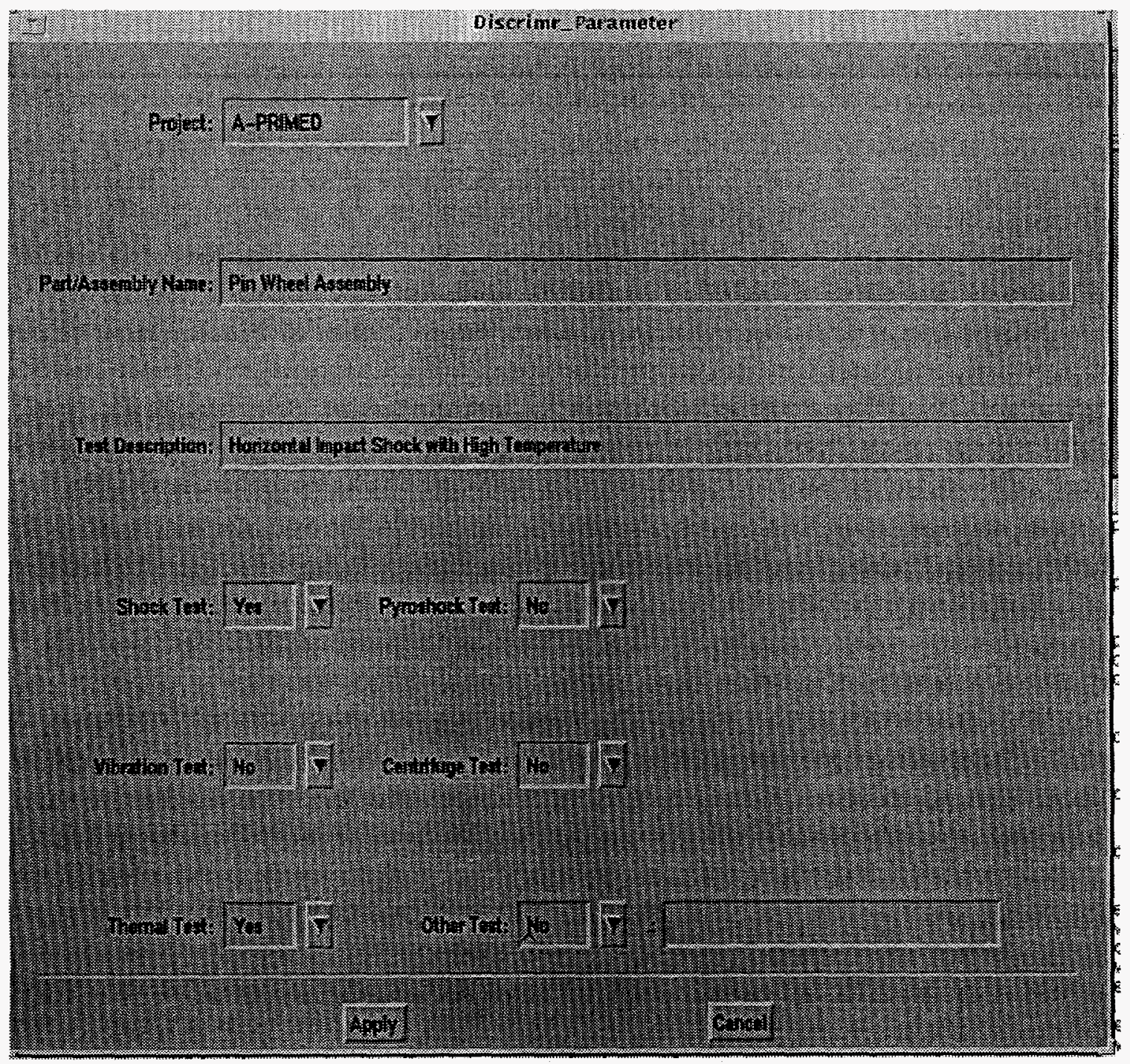

